\title{
$2^{N D}$ INTERNATIONAL CONGRESS ON CLINICAL \& COUNSELLING PSYCHOLOGY (CPSYC) 2014
}

\section{Abstract Book}

Editors:

Dr Zafer Bekirogullari \& Melis Y. Minas

e-ISSN: $2301-2226$

e-ISSN number is registered by the ISSN Cyprus Centre (European Union)

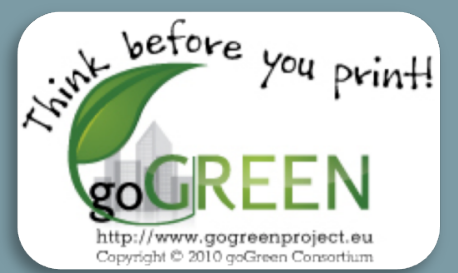

Please consider the Environment before printing

It will not be printed by Future Academy

(it is available online only)

$1^{\text {st }} 4^{\text {th }}$ December, Limak Lara Hotel, Convention Centre, Antalya/TURKEY 
http://dx.doi.org/10.15405/cpsyc2014(2301-2226)

\section{Table of Contents}

CPSYC 2014 Chairs' Message 5

Scientific Committee \& Board of Reviewers 7

Future Academy ${ }^{\circledR}$ 's Multidisciplinary Conference 2015

Effects of forgiveness therapy on recovery among residents of drug $\begin{array}{ll}\text { rehabilitation centers } & 10\end{array}$

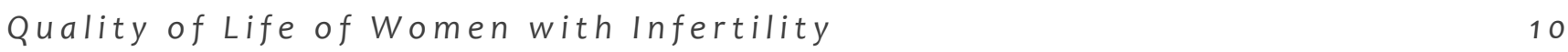

Understanding the impact of suicide on the families of the deceased 11

Lateralization and Marital satisfaction $\quad 11$

The Perception of Psychotherapy in Turkey 12

Mental health promotion and prevention among gifted adolescents 12

Investigating Mental IIIness Stigma in Turkish and Greek Cypriots living in

Cyprus 13

A phenomenological analysis being seen \& showing 14

What's it like being you? Growing old(er) with Autism Spectrum Conditions

Improving autonomy and social participation with a home-based exercise program

Do you feel what I feel? Emotional development in children with ID

Effectiveness of Mindfulness therapy among adolscents with conduct

disorder in Jakarta $\quad 16$

Effects of Teaching Creativity on Improving University Students' Creativity and Innovation

New Leadership Model of the University Management for Innovation and Entrepreneurship 18

Effects of Self-Efficacy and Emotional Intelligence on Preventing Mobbing at

University Environments

Effects of Social Ecosystem on Improving Creativity, Innovation, and

$\begin{array}{ll}\text { Technological Development } & 20\end{array}$

Characteristics of problem situations of students appealing to SPbSU psychological center

"Naked genes" as health innovation: a challenge for psychological research

Integrated Motivational Interviewing with Brief Strategic Therapy for Heart patients

Family Life Space (FLS): Emerging Couple Bonds

Health Care Access - Case of Slovakia

Counselling network ties of Polish emigrants in the UK 
Symbols of healing and transformation in analytical psychotherapy: The bridge

Teachers in Distress: Counselling Needs of Secondary Teachers in Roumania

Subcultural Narratives of Pediatric Chronic Illness in the Arab Community 27 Minority ethnic identity and discrimination experience in a context of social transformations

Attachment and affection relations in a family: aspects of child attachment

Social physique anxiety and it's relation with body dysmorphic disorder Integrated Motivational Interviewing with Brief Strategic Therapy for Heart patients

The cross-cultural application of the DSM-V

Unexplained anticipatory activity in patients with traumatic brain injury ( $T B I$ )

Communication from 'bruises' to Ipad

Contributions to the quality of life of chronic renal insufficient

The Study of Relationship Between Attachment Styles and Obsessive Love Style

Neuropsychological functioning in Obsessive-Compulsive washers 34

The impact of brain injury on emotional intelligence

Internet supported Cognitive Behavior Therapy to help students with shysocially isolated problems

Structured peer group supervision: Utility and benefits

Health beliefs about cervical cancer in university students

Self-harming behavior and its relation to previous psychological or psychiatric care

Learning strategies and academic performance

Mediating-effect of Narrative-Identity and Self-Esteem in relationship between Self-Focused Attention and Depression

Self-esteem and hopelessness as predictors of emotional difficulties among adolescents in Kosovo

The Moderating Effect of Age on Relationships of Self-Compassion, SelfEsteem, Mental Health

$1^{\text {st }}-4^{\text {th }}$ December, Limak Lara Hotel, Convention Centre, Antalya/TURKEY 
Mediating effect of anxiety on relationship between inter-parental conflict and students' self-efficacy

The Authoritative Syndrome in Attitudes and Educational Practices of Russian Parents

Dating... making out... Young girls' relationships experience in the affective-sexual sphere

Brain Dynamics of Mild Cognitive Impairment (MCI) from EEG Features

Evaluation of implementation of a psychoaffective Education program to schooled children

The Moderating Effect of Gender: Traumatic Experiences and Depression in Adolescence

Confirmatory Factor Analysis of the Resilience Scale (RS13-A) in Portuguese

Adolescents

Confirmatory Factor Analysis of the QRI Father's Version in a Portuguese Sample

Cognitive Emotional Regulation Strategies and Depressive Symptoms:

Gender's Moderating Effect 


\section{CPSYC 2014 Chairs' Message}

We are honoured to chair the International Congress on Clinical and Counselling Psychology (CPSYC) to be held in Antalya from December 1st to 4th 2014. We hope that clinical and counselling psychologists, practitioners, students, researchers and others from around the world will consider attending this meeting and that many of you will submit papers and posters. We have a talented and committed team of CPSYC Scientific Committee and Board of Reviewers who are working hard to make the 2014 Congress a resounding success.

We will meet in Antalya, Turkey, which is one of the most lively and friendly cities in the world. The Congress will not only build on the success of previous Ccrcs conferences and congresses, but will also continue to seek to raise the bar in international exchange of ideas, collaborations, and cooperation among academics, clinical psychologists, counselling psychologists, and other practitioners.

The 2014 Congress will provide excellent opportunities for participants to exchange ideas with each other. It will facilitate discussions, including challenges to clinical and counselling psychology; it will provide an international forum for scientific debate and constructive interaction. Furthermore, it will provide a platform for educators, researchers, students, and practitioners to present their work; exchange knowledge, ideas, and experience; and identify solutions to existing challenges in clinical and counselling psychology. Doctoral candidates are particularly invited to present and discuss their research ideas and work in progress.

The committee has decided to include pre-conference continuous professional development workshops, poster presentations, and Special Interest Group (SIG) symposia. To this end, the CPSYC 2014 Scientific Committee and Board of Reviewers welcome papers from the following and related topics:

Anxiety Disorders, Attention Disorders, Autism, Behavioural Science, Behavioural Therapy, Child Psychology, Chronic Diseases, Clinical Psychology, Clinical Research, Cognitive-Behavioural Therapy, Community Health, Depression, Eating Disorders, Ethics, Forensic Science, Gay and Lesbian Issues, Genetics, Health Care Access, Health Care Financing, Health Economics, Health Policy and Promotion, Health Services Innovations, Health Services Research, Intellectual Disabilities, Marriage and Family Therapy, Medical Ethics, Mental Health, Minority Health, Neuropsychology, Outcome Research, Paediatrics, Preventive Medicine, Psychiatry, Psychopathology, Psychotherapy, Public Health, Quality of Life, Research Methods, Schizophrenia, Sexual Violence, Social Science, Social 
Work in Medicine, Substance Abuse, Suicide and Violence Prevention.

As in previous conferences and congresses of C-crcs, abstracts from the 2014 Congress will be published by C-crcs, and full-text papers will be provided by Elsevier in the CPSYC 2014 Proceedings or by C-crcs in the peer-reviewed Volume as a book chapter

Previous C-crcs conferences and congresses have been very successful, and CPSYC 2014 promises to be another high quality event. Antalya, itself is a small, beautiful city which is easy to travel around so visitors can take the opportunity to have a holiday there.

We look forward to meeting with colleagues and friends-old and new-in Antalya in December, 2014 .

Barbara A Wilson

Co-Chair CPSYC 2014

OBE, Ph.D, CPsychol, ScD, FBPsS, FMedSci, AcSS

President of the Encephalitis Society

Member of the Management Committee of The World Federation of Neuro

Rehabilitation

Pavlo Kanellakis,

Co-Chair CPSYC 2014

CPsychol, CSci, FBPsS

Chartered Psychologist Specialising in Psychotherapy (British Psychological Society)

Health and Care Professions Council UK Registered Clinical, Counselling and Health Psychologist

British Association for Behavioural and Cognitive Psychotherapies Accredited Therapist, Supervisor and Trainer

IPT UK Accredited Interpersonal Psychotherapist and Supervisor Association for Psychological Therapies Accredited Trainer 


\section{Scientific Committee \& Board of Reviewers}

Abdullah Najat, PhD, Kuwait University, Kuwait

Ahmad Iftikhar, PhD, University of Management and Technology C-II, Johar Town, Lahore, Pakistan

Al Issaei Nadiya, PhD, College of Sohor for Applied Sciences, Oman

Almahdi Ali Elwan, PhD, Al Fateh University, Libya

Alois Ghergut, PhD, Alexandru loan Cuza University, Iasi, Romania

Alswaidan Enas, PhD, Kuwait University, Kuwait

Ana Canen, PhD, Federal University of Rio de Janeiro, Brazil

Anita Welch, North Dakota State University, USA

Anna Slysz, PhD, Adam Mickiewicz University in Pozna, Poland

Arce-Mekina Enrique, PhD, IPN, Mexico

Arshin Adib-Moghaddam, PhD, SOAS, University of London UK

Asano Sachiko, PhD, Osaka University of Health and Sport Sciences, Japan

Binnur Yesilyaprak, PhD, Ankara University, Turkey

Carmel McNaught, PhD, The Chinese University of Hong Kong, China

Cheng Robin, PhD, Taylor's University, Malaysia

Clipa Otilia, PhD, University "Stefan cel Mare" of Suceava, Romania

Conni Campbell, PhD, Point Loma Nazarene University, USA

Cruz Sandra Silvia, PhD, O Porto Nursing College, Portugal

David Kennedy, PhD, Lingnan University, Hong Kong

Demetrios Sampson, PhD, University of Piraeus \& CERTH, Greece

Despoina Filiou, PhD, Manchester Metropolitan University, UK

Elena Lupu, PhD, Petroleum-Gas University of Ploiesti, Romania

Elvin Kerime Silahtaroglu, PhD, Cag University, Turkey

Ezeh Cecilia Obioma, u PhD, FCE, Eha Amufu, Emugu State Nigeria

Farag Elbla Alawia Ibrahim, PhD, Ahfad University for Woman, Sudan

Felice Corona, PhD, University of Salerno, Italy

Figen Cok PhD Baskent University Turkey

Franco Fortunati, PhD, University of Bologna, Italy

Geanina Masari PhD Al. I. Cuza University Iasi Romania

Gregory Poole, PhD, University of Tsukuba Japan

Hasan Bacanli, PhD, Gazi University, Turkey

Hayder Yagoob, PhD, Diala University, Iraq

Heikki Ruismaki, PhD, Helsinki University, Finland

Hilary Cremin, PhD, University of Cambridge, UK

Hoven Debra, PhD, Athabasca University, Canada

Hsing Chin Lee, PhD, National Taipei College of Business, Taiwan

Hugh Glenn, PhD, Deputy President, Future Academy, United States

Ignat Aurora Aidina, PhD, University "Stefan cel Mare" of Suceava, Romania

Inkeri Ruokenen, PhD, Helsinki University, Finland

James Johnson, PhD, Point Loma Nazarene University, USA

James Ogunleye, PhD, Middlesex University, UK

Jan Vermunt, PhD, University of Cambridge, UK

Jan Bamford, PhD, London Metropolitan University, UK

Jan Kalenda, PhD, Tomas Bata University, Czech Republic

$1^{\text {st }}-4^{\text {th }}$ December, Limak Lara Hotel, Convention Centre, Antalya/TURKEY 
Jumani Nabi Box, PhD, International Islamic University Islamabad, Pakistan

Kauko Komulainen, PhD, Helsinki University, Finland

Kelly O'Brian, PhD, University of Melbourne, Australia

Leonor Santos, PhD, Universidade De Lisboa, Portugal

Lonka Kirsti, PhD, University of Helsinki, Finland

Macleans Geo-Jaja, PhD, Brigham Young University, Utah, USA

Mangunsong Frieda, PhD, University of Indonesia, Indonesia

Margarita Vives Barceló, PhD, Universitad de las Islas Baleares, Spain

Maria Do Rosario, Pinheiro, PhD, University of Coimbra, Portugal

Maria Teresa Diaz Mohedo, PhD, University of Granada, Spain

Marie Myers, PhD, Queens University, Canada

Mehmet Ali Dombayci, PhD, Gazi University, Turkey

Mihaela Badea, PhD, Petroleum-Gas University of Ploiesti, Romania

Nachoua Hassina, PhD, Rohamad Kheider Biskra, Algeria

Nadia Idri, PhD, Abderratmane Mira-Bejava, Algeria

Nagabhoshan Prathiba, PhD, The Australian National University, Australia

Nasreen Hussain, PhD, Aga Khan University, Pakistan

Navehebrahim Abdol, PhD, Kharazmi University, Iran

Patricia Almeida, PhD, University of Aveiro, Portugal

Phuc Nguyen, PhD, Arkansas State University, USA

Quiaoyan He, PhD, Sichuon Normal University, China

Ritland Valerie, PhD, Minnesota State University Moorhead, USA

Safta Cristina, PhD, University of Ploiesti Petroleum Gas, Romania

Salima Rahebi, PhD, Mohamed Khider, Algeria

Santos Catia, PhD, Unidade Local de Saúde de Matosinhos, Portugal

Shahrokh Shafaie, PhD, Southeast Missouri State University, USA

Shaukat Saida, PhD, University of Education, Pakistan

Sozinov Alexey, PhD, Institute Of Psychology Russian Academic Sciences, Russia

Stan Emil, PhD, Petroleum-Gas University of Ploiesti, Romania

Suppiah Nachippan, PhD, Sultan Idris Education University, Malaysia

Tapio Tovanen, PhD, Helsinki University, Finland

Tayyar Sen, PhD, Toros University, Turkey

Tolegenova Aliya, PhD, Kazakh National University, Kazakhstan

Ugur Oner, PhD, Cankaya University, Turkey

Val Chapman, PhD, University of Worcester, UK

Vasile Cristian, PhD, Petroleum Gas Ploresti, Romania

W.C.M. (Willibrord) Weijmar Schultz, MD, University Medical Center Groningen, Netherlands

Yuzhi Cai, PhD, Swansea University, UK

Zafer Bekirogullari PhD, Managing Director, Future Academy, UK

Zaki Boudy, PhD, King Faisal University, Saudi Arabia

$1^{\text {st }}-4^{\text {th }}$ December, Limak Lara Hotel, Convention Centre, Antalya/TURKEY 


\section{Future Academy's Multidisciplinary Conference 2015}

Future Academy's Multidisciplinary Conference will meet in Istanbul in $13-17$ October 2015. This multidisciplinary conference also serves to celebrate the 8 th anniversary of Future Academy, formerly known as Cognitive C-crcs Counseling, Research \& Conference Services. Participants will attend individual conference and congress presentations as well as multidisciplinary presentations.

This conference brings together these annual events:

- 6 th International Conference on Education \& Educational Psychology (ICEEPSY)

- 3rd International Congress on Clinical \& Counselling Psychology (CPSYC)

- $\quad 2$ nd International Conference on Business \& Economics (BE-ci)

- 2 nd International Conference on International Relations \& Sociology (icPSIRS)

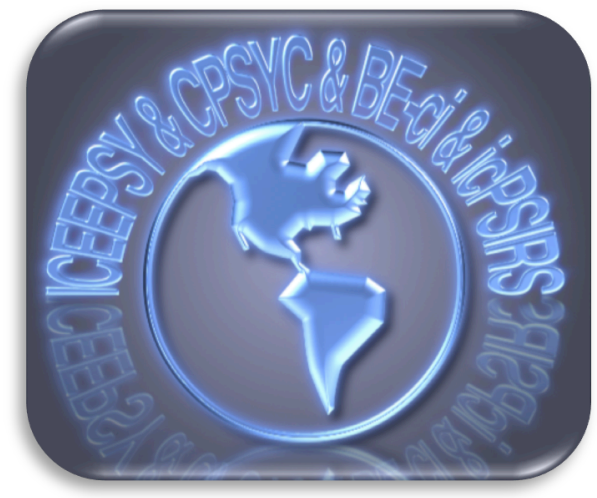

This multidisciplinary conference presents an opportunity for members of the several academic communities-researchers, professors, teachers, practitioners, and vendors-to gain new knowledge and skills, to interact, and to share research findings in Presentations, abstracts and complete papers, will be published in the proceedings of each conference.

Multidisciplinary Conference is organized by:

The Future Academy ${ }^{\circledR}$ 


\title{
1869
}

\author{
Effects of forgiveness therapy on recovery among residents of drug \\ rehabilitation centers \\ Myrtle Orbon*, Jocelyn Mercado, Jolly Balila \\ "University Research Center, Adventist University of the Philippines, Silang, Cavite \\ 4118 , Philippines
}

The study determined the effects of forgiveness therapy on the residents' recovery. Recovery includes the residents' level of risk of relapse and gratitude. The participants of the study were the residents admitted for drug treatment and rehabilitation in a government-based drug rehabilitation center in the Philippines. The experimental group $(N=29)$ was exposed to a $12-s e s s i o n$ forgiveness therapy whereas, the control group $(N=29)$ was exposed to traditional method of treatment and rehabilitation program. The results show that forgiveness therapy decreased the level of risk of relapse and increased the level of gratitude of the experimental group. However, the level of risk of relapse and the level of gratitude of the control group did not change. The study implies that the participants who underwent forgiveness therapy sessions showed improvement in their recovery than those who were exposed only to traditional treatment method of the center.

\section{4}

\section{Quality of Life of Women with Infertility}

Manuela Ferreira*, Sandra Vicente, Joao Duarte, \& Claudia Chaves

*Superior Health School, Polytechnic Institute of Viseu, Rua D. João Crisóstomo Gomes de Almeida, no $102,3500-843$ Viseu, Portugal

Background: Procreation and the wish to start a family is one of the natural needs of human beings and one of the important pillars of their quality of life. It is subject to emotional and marital impacts which may contribute to pregnancy failure. Objectives: To identify determinants that influence the quality of life; to determine whether socio demographic variables impact the quality of life of women with infertility; to verify the influence of contextual variables of infertility on the quality of life of women. Methods: A quantitative study with 106 women with a diagnosis of infertility. Data collection was carried out through a questionnaire consisting of a socio-demographic component, obstetric history and a scale WHOQOL - Brief (Abbreviated Instrument for Assessment of the Quality of Life of the World Health Organization). Results: The average age was 33 years; 62.3 \%have never been pregnant and $51.9 \%$ have been trying to get pregnant for more than 3 years. There is a relationship $(p<0.05)$ between age, schooling, number of previous pregnancies, type of treatment used in case of missed abortion, duration of menstruation, infertility and quality of life. Conclusion: Updating knowledge has become increasingly important for health professionals, aiming for the improvement of the quality of life of women 
ffh c confronted with a diagnosis of infertility. These results are consistent with those obtained by other studies that validate the change in quality of life, according to several socio-demographic characteristics, obstetric history and infertility diagnosis.

\section{0}

\section{Understanding the impact of suicide on the families of the deceased Farzana Ali* \\ "School of Human and Health Sciences, University of Huddersfield, Queensgate, Huddersfield, West Yorkshire, United Kingdom, HD1 3DH}

Statistics indicate a projected increase in the number of suicides by those in receipt of mental health services in England. Research has also shown that the impact of suicide on individuals who have lost someone to suicide have an increased risk of poor physical and mental health, including a higher risk of suicidality. However, research within suicide bereavement is limited due to the lack of methodologically robust studies involving those bereaved through suicide. This paper will offer an overview of current debates in the suicide bereavement literature and discuss a forthcoming qualitative study that will examine the impact of suicide by those in receipt of mental health services on their families. The current research will utilise a constructivist grounded theory approach. Analysis of the data will include a process of coding and comparison, leading to theory generation. This study aims to contribute to knowledge of the impact of suicide on family members (where the deceased was in receipt of mental health services) and how to provide effective post-intervention support for these particular families.

\section{7}

\section{Lateralization and Marital satisfaction}

Farnaz Holekian*, Yaser Madani, Masoud Gholamali Lavasani

*Family counseling MSc, University of Tehran, Tehran, Iran

The purpose of this study was to investigate the relationship between lateralization and marital satisfaction. The samples consisted of couples in the Iranian city of Hamedan, of whom 200 participants (100 couples) were randomly selected through cluster sampling. Data collection tools used included Enrich couple scales and demographic questionnaire that were made by the researchers. For data analysis, in addition to descriptive statistics, coefficient of rho$1^{\text {st }}-4^{\text {th }}$ December, Limak Lara Hotel, Convention Centre, Antalya/TURKEY 
spearman correlation and multiple regression were used. Data analysis identified that left-handedness and right-handedness did not show don't have significant correlation with marital satisfaction ( $p>0.05)$. But mixed manual preferences (nopreference for either hand) has significant correlation with marital satisfaction $(p<0.01)$. Therefore, it can be concluded that marital satisfaction seems to be correlated with lateralization.

\section{3}

\section{The Perception of Psychotherapy in Turkey} Deniz cosan*

*Keele University, Keele, Staffordshire ST5 5BG, United Kingdom, +44 1782732000

This research explores the perception of psychotherapy in Turkey. The main aim of this study is to understand participants living in Turkey in relation to their views and experiences of psychotherapy, and to examine several aspects of the perception of psychotherapy in Turkey by using in-depth interviews with twenty participants. Some themes are highlighted by using the information gathered by interviews. These include: the family is very important in Turkish culture and so the family's attitude affects people's views and experiences; keeping family secrets hidden is valued, so telling them to a psychotherapist in order to solve them may not be a solution; the high cost of private psychotherapy in Turkey is the main factor affecting people's attitudes towards it; state hospitals, in which psychotherapy services are free, may not be preferred because of negative beliefs about state workers and state hospitals. The data gathered may present some shared views of the Turkish people, however it is important to consider that, Turkey has a large population and a homogenous culture including many different languages, religions, sects, habits, views and life styles, so it is not possible to reflect all.

\section{9}

Mental health promotion and prevention among gifted adolescents Zsuzsanna Suranyi ${ }^{*}$, Emoke Bagdy, Zsuzsanna Mirnics

*Assistant Professor at Károli Gáspár University, Hungary

Problem Statement: Mentoring gifted adolescents usually focus on developing the skills, in which individuals have talents. However, psychological assistance may be needed in cases of stress or coping with failures. Research Questions: What psychological difficulties/ mental health problems are prevalent among gifted adolescents and how psychologist can help them? Purpose of the Study: We have provided 100 gifted adolescents a one-year long psychological assistance (including 30 hours individual conversation with a clinical psychologist, 30 hours group workshops and a 5-day long summer-camp). The 
purpose of the study was to unfold their psychological problems and to examine the impacts of therapy. Research Methods: We used both quantitative and qualitative methods, examining the gifted young individuals as well as their teachers and parents. The clinical psychologists also provided a thorough casedescription and filled out a questionnaire about each individual. Young individuals filled out Parent and Peer Attachment, Olson FACES-IV, State-Trait Anxiety Inventory, Child Depression, IPIP personality, Creativity, Flow, Motivation and Interests, Self-esteem test. Findings: We have identified eight areas of psychological problems (Environmental, Social, Emotional, Motivational, Cognitive, Self-esteem, Coping, Organizational problems) five typical psychological profiles of the gifted individuals (introverted-anxious, perfectionist, seeker, problematic, resilient). Psychological counselling turned out to be most effective in reducing stress and developing coping skills. Conclusions: Individual psychological mentoring turned out to be the most efficient for gifted adolescents. The young gifted individuals liked to learn relaxation techniues, copinig strategies and most importantly they appreciated the non-critisizing, positive, encouraging atmosphere they experienced at the psychologist.

\section{1}

\section{Investigating Mental IIIness Stigma in Turkish and Greek Cypriots living in Cyprus}

Akile Berfu Zorba*

"Middlesex University of London, United Kingdom

Problem Statement: Although there is much research on attitudes towards mental illness, none has been made which looks into and compares the Turkish and Greek Cypriot populations. Research Questions: Is there a stigma in Turkish and Greek Cypriot communities towards mental illness and are they similar, do these cultures fit in within the individualism-collectivism concept? Purpose of the Study: The main aim of this research is to gain a deeper understanding about the levels and causes of mental health stigma that exists in Turkish and Greek Cypriot communities living in Cyprus. Research Methods: Quantitative methodology was used in this researcher. For this purpose the researcher used 4 different scales. Knowledge Questionnaire Corrigan's Attitude Scale (AQ, 27) Level of Familiarity Scale (LOF) Vertical-Horizontal Individulalism - Collectivism Scale (Triandis, 1995) Findings: The results showed the existence of mental illness stigma in both Turkish and Greek-Cypriots. Turkish - Cypriots, however, significantly held more negative attitudes towards individuals with mental health problems. There was a difference in culture where Turkish-cypriots were also 
found to be significantly more vertical-collectivists while Greek-cypriots were significantly more familiar with mental health problems. They did not differ in their knowledge. Conclusions: In conclusion, mental illness stigma is a common problem around world that has a negative impact on those who are affected. Stigma was also prevalent in both Greek and Turkish Cypriot populations. Turkish Cypriot being more stigmatised towards mentally ill. It was also found that Greek and Turkish Cypriot culture could be explained using individualism-collectivism dimension.

\section{3}

\section{A phenomenological analysis being seen \& showing Olivia Sagan* \\ "Bishop Grosseteste University Lincoln, United Kingdom}

Problem Statement: To understand the role of art practice in the life of someone diagnosed with Borderline Personality Disorder. Research Questions: How does visual art activity offer a means of accessing mentalization processes in the life of an individual diagnosed with Borderline Personality Disorder. Purpose of the Study: To employ a longitudinal, phenomenological, first person narrative approach to understanding the function of an art practice in the life of a long term mental health service user. Research Methods: Interpretative Phenomenological Analysis (IPA) First person narrative Findings: Findings suggest that the process of building a narrative identity through the deliberate, if unconscious requirements of a social art practice was facilitating a safe zone of relating and forming group attachments. Conclusions: The study suggested that the gradual process of coming to be seen and showing, relating and narrating, was part of a dynamic process in which the artist's improving mental health and autobiographic art practice informed and strengthened each other. The study offers pointers regarding the role of art practice in offering a language and connectedness otherwise inaccessible to some.

\section{7}

\section{What's it like being you? Growing old(er) with Autism Spectrum Conditions Frauke Elichaoff* \\ "Middlesex University, London, United Kingdom}

Problem Statement: Autism (ASC) is a lifelong disorder, yet there is very little research on aging with ASC, and what the experiences and needs are for older adults. Research Questions: What are the subjective lived experiences of older adults with ASCS? Purpose of the Study: To gain an understanding the lived experiences of older adults with ASC. This will add to the fragmented picture 
that the currently available research presents. Do symptoms increase or ameliorate? Do they develop coping skills? How does the diagnosis affect their experiences of ASC? Research Methods: A phenomenologically driven qualitative study using semi-structured interviews with adults with ASC. A scoping study to identify salient topics, which are then explored in-depth through a a series of interviews with adults with ASC as well as key informants such as siblings and caregivers. Findings: The following themes were identified as representing the salient issues the participants talked about during their interviews: the effects of the diagnosis, depression, experiences with mental health professionals, the inverted relationship between educational level and lack of career, the participant as autism expert, and communication/social interactions.. These topics will form the basis for follow-up interview series. Conclusions: The lack of available research on aging with ASC is a serious issue as there is a growing population of older adults with ASC. This research adds to the understanding of the lived experiences of these adults, which complements current ongoing research that focuses on cognitive and physical aspects of aging with autism.

\title{
2048
}

\author{
Improving autonomy and social participation with a home-based \\ exercise program \\ Vítor Pinheira*, Mariana Aparício, Nuno Cordeiro \\ *Physiotherapist Polytechnic Institute of Castelo Branco, College of Health Dr. \\ Lopes Dias, Castelo Branco, Portugal
}

Problem Statement: The home-based exercises programs are a method to promote health, quality of life and autonomy of elderly. Low levels of adherence are the major problem of these programs. Research Questions: Why did elderly people change from a home-based exercise program to a group program? Which are the results of this change after three and six months from the exercise program? Purpose of the Study: To evaluate the adherence to a home-based exercise and understand how the participants transformed the author's protocol into a group experience. To evaluate the participants reasons to make this change. Research Methods: The study was made in a Portuguese rural community; initial sample of 15 subjects who performed a home-based exercise program, during 8 weeks. The program was later transformed into a group program. Balance, mobility, cognitive state, health state and depression were evaluated also at 3 and 6 months after the program. A final interview revealed the opinions of the participants about the group program. Findings: Adherence to the home-based exercise program revealed that participants recognized the value of the program and this is expressed in the creation of a community group. Conclusions: Social

$1^{\text {st }}-4^{\text {th }}$ December, Limak Lara Hotel, Convention Centre, Antalya/TURKEY 
participation of elderly in a Portuguese small rural community was developed with a home-based exercise program, and its transformation in a group program.

\title{
2050
}

\author{
Do you feel what I feel? Emotional development in children with ID \\ Cristina Maria Gonçalves Pereira, Sónia Maria de Matos Faria* \\ *Cristina Maria Gonçalves Pereira-PhD Escola Superior de Educação do Instituto \\ Politécnico de Castelo Branco, 6000-266 Castelo Branco - Portugal
}

Do you feel what I feel? Emotional development in children with ID is a study that has emerged as a need to deepen the knowledge on this area. It has focused in a case study methodology with the use of three validated instruments to a sample of thirty-four children, twenty attending the $1^{\text {st }}$ cycle and fourteen attending the $2^{\text {nd, }}$ in two school groupings of Castelo Branco city. Seventeen of them have mild intellectual disability and seventeen are "normal", aged between 8 and 14 . The research has been developed in order to give answers to questions related with the way that children with intellectual disability (ID) express, identify and regulate their emotions. The results suggest that children with intellectual disability identify emotions, in a general way, the same way that "normal" children do, nevertheless, there are some difficulties in the understanding and organization of coping strategies.

\section{2}

\section{Effectiveness of Mindfulness therapy among adolscents with conduct disorder in Jakarta}

Suzy Yusna Dewi ${ }^{*}$, Martina Wiwie, Sudigdo Sastroasmoro, Irwanto, Jan S. Purba, W. Edith H. Pleyte, Mulyono, Fatimah Haniman

* Soerharto Heerdjan Mental Health Hospital, Minister of Mental Health

Background and objectives: The prevalence of adolescent conduct disorder (CD) among school in Jakarta is $26,1 \%$ leading to high incidence of student brawls. Up until now, there is no structured module for CD intervention that can be done by teacher, thus mindfulness therapy is used in scholl to reduce such incidence. The objective of this study is to asses the effectiveness Learning of self-regulation in mindfulness therapy conducted by school counselor inmitigating their involvement in brawls and other forms of violence. Changes in behaviour and cortisol level are used as indicators of success. Method: subject were randomly assigned into treatment as usual (with school counselors) and into Mindfulness training by counselors supervised by a psychiatrist. Cortisol level was checked before and after treatment. Behavioral changes were reported trough a conduct disorder instrument developed for the study. Outcome data was analized using Chi-square, Odd Risk Ratio calculation, and the General Linear Model Repeated

$1^{\text {st }}-4^{\text {th }}$ December, Limak Lara Hotel, Convention Centre, Antalya/TURKEY 
Measures. Results and conclusion: 103 students completed the study (intervention $n=53$ control $n=50$ ) after 8 weeks, showing the effectiveness of Mindfulness therapy by $N N T=2, R R=3,40$ (2,04-5,65. The secondary results showed a decrease of anti-social behaviour measured by TCD-AM and a significant decrease of serum cortisol level (po,oo) compared to the control group. Minfulness therapy recomended to manage anti-social behavior in school. Learning of self-regulation in mindfulness therapy resulted in improvement of emotional and behavioral control among adolescent with conduct disorder. Minfulness therapy can be conducted by school counselors after appropiate training. This study is limited among male adolescents with mild and moderate history of conduct disorder. Girls and the experienced severe conduct disorders were not included in study.

\section{6}

\section{Effects of Teaching Creativity on Improving University Students' Creativity and Innovation}

Gamze Sart*

"Istanbul University, Turkey

Problem Statement: The learned abilities of the university students in creatively to develop innovative goods and services have become unique problems for all the best universities in the world. Research Questions: In this study,how the universities can affect on fostering creativity is analyzed as a research question. Therefore, the universities role as environmental opportunities is critically questioned on creativity and innovation Purpose of the Study: The main purpose of this study is to understand clearly how, where, when, and with whom creativity and innovation can foster among the university students. Additionally, the strategy of delivering creativity for innovative products and services is another aspect of this study to analyze the implementation of creativity in the process Research Methods: By using phenomenological analysis, fostering creativity and innovation is analyzed and observed for eight weeks in five different environments and 12 different research questions were answered in the semi-structured interviews during the sessions. The collected data were analyzed in Atlas.ti 7 in order to make depth study. Data analysis of this research included computer assisted coding for deductive reasoning Findings: Most ( $88 \%$ ) agree that the fostering creativity and innovation is possible in active learning by doing different projects in a team. Some (67\%) clearly mention that fostering creativity and innovation should begin in the freshmen year, instead of the senior year. The large number ( $89 \%$ ) cannot find any place to collaborate with others hence they need a common place Conclusions: The strategy of delivering

$1^{\text {st }}-4^{\text {th }}$ December, Limak Lara Hotel, Convention Centre, Antalya/TURKEY 
creativity for innovative products plays an important role. The university has policy to empower creativity and innovation in the university years. The curricula and extracurricular activities may change to foster creativity and innovation in the university environment. The implication strategy should meet the needs of today's changes in the development of the technology based innovative products

\section{9}

\section{New Leadership Model of the University Management for Innovation and Entrepreneurship}

Gamze Sart*

*Istanbul University, Turkey

Problem Statement: Creating a learning environment for innovation and entrepreneurship depends on the leadership model of the university management because of the highly technological and innovative products and services demand. Research Questions:This study questions the leadership model at the universities where innovation and entrepreneurship have significantly improved including the drawbacks of the leadership models. Purpose of the Study: As the purpose of this study, the new leadership model for the university management for innovation and entrepreneurship is studied clearly to understand deeply the new roles in these highly competitive global economies. Furthermore,the style of the leadership model is analyzed as well to find out the new strategy. Research Methods: By using strategically phenomenological interpretive analysis,the new leadership model for the university management for innovation and entrepreneurship is articulated in three different universities in Istanbul. The study takes three months where 42 different faculty members and 12 graduate students are questioned by giving 6 different research questions in the semistructured interviews.The data are analyzed in Atlas.ti 7. Findings: The participants ( $78 \%$ ) mention the participatory democracy is important as the new leadership model to empower innovation and entrepreneurship.ln the new leadership management,most (79\%) clarify the role of intensive collaboration with the members of the industry who play important role in the management.In the transformation of the university,the participants (69\%) agree the experts should be taken into consideration Conclusions: The strategy of the leadership model may be more open and democratic for open innovation. In the new management, the leaders create new environments and spaces, like technology transfer offices to collaborate with the industry. In some cases, the university management has conservative and traditional leaders who discourage innovation and entrepreneurship. In these cases,most of the members leave the institution 


\section{5}

\section{Effects of Self-Efficacy and Emotional Intelligence on Preventing Mobbing at University Environments} Gamze Sart*

*Istanbul University, Turkey

Problem Statement: Mobbing is one the serious problems at work,such as the universities work environments. Preventing mobbing in these environments where most of the people are highly intellectual is not easy. Research Questions: In this study, what are the effects of self-efficacy and emotional intelligence on preventing mobbing at university environments is critically analysed,and what kind of prevention methodology is needed is overviewed. Purpose of the Study: The purpose of this study is analyzing the effects of self-efficacy and emotional intelligence on preventing mobbing at university environments. By developing new curricula and new preventing ecosystems, new approaches are analyzed to diminish significantly mobbing, particularly undeclared ones and to increase awareness in the university work environments Research Methods: By using two instruments named Emotional Intelligence and Self-Efficacy Test, the effects of the new interactive curricula and social environment, including social media, as new ecosystem at one university are analyzed as an experimental research. The pre and post-test are given to the three different experimental groups, including the control groups. The collected data are analyzed by using SPSS. Findings: The results show the curriculum, where emotional intelligence and self-efficacy is combined in the social ecosystem, is $66 \%$ effective on preventing mobbing. The curriculum where just emotional intelligence skills are given is $46 \%$ effective in preventing mobbing.In the curriculum,where only self-efficacy skills are motivated, $28 \%$ effective on preventing mobbing.In the results of the control group,however,significant difference is not seen. Conclusions: As a result, the self-efficacy and emotional intelligence combined curriculum in the social ecosystem affects significantly on preventing mobbing at university environments where people's awareness and empathy have increased. Emotional intelligence and self-efficacy skills help people to behave properly in the university environment. More importantly, people who have been oppressed, find better opportunities to express their situations. 


\section{8}

\section{Effects of Social Ecosystem on Improving Creativity, Innovation, and Technological Development}

Gamze Sart*

*Istanbul University, Turkey

Problem Statement: In the development of creativity,innovation,and technological development,different social environments affect significantly the success at the universities. Thereforesocial ecosystems,where social media,Facebook and Twitter,are interactively used,have significantly transformed and transcended ecosystems Research Questions: In this study, what the effects of social ecosystem are on improving creativity, innovation, and technological development is critically analyzed.Additionally, how social media affects the social ecosystem is questioned Purpose of the Study: The purpose of this study is analyzing critically the impacts of social ecosystem, particularly in those where social media are interactively used on improving creativity, innovation, and technological development. By developing a new social ecosystem with social media, university students' behaviors and attitudes on creativity, innovation, and technological development are questioned Research Methods: Phenomenological interpretive analysis is used to investigate, in a new social ecosystem with social media, the university students' behaviors and attitudes on creativity, innovation, and technological development in two different universities. The study takes five months 36 undergraduate and 8 graduate students who answered 6 different research questions in the semi-structured interviews.The collected data are analyzed in Atlas.ti 7 Findings: Most of the participants (97\%) agree that they need a new social ecosystem in which they can collaborate and share their ideas through closed and opened social media. Most ( $86 \%$ ) clarify that their behaviors and attitudes change because their selected attention and awareness are improved. The interactive communication and teamwork capacity have increased according to the participants (79\%). Conclusions: As a result, the participants complain about the mentality of their universities comparing to the other universities in the US in which social ecosystem is encouraged and empowered by social media.In the light of this evidence, social ecosystem, particularly with social media affects significantly on improving creativity, innovation, and technological development in the undergraduate level students comparing to graduate level students. 
2094

Characteristics of problem situations of students appealing to SPbSU psychological center

Kostromina Svetlana*, Zinovyeva Elena, Beykina Alexsandra

*St. Petersburg State University, 199034, Universitetskaya embankment, 7-9,

St.Petersburg, Russian Federation

The Article based on 390 cases of the psychological consulting practice describes the content of different types of problematic situations typical for students depending on the year of study (age) and chosen profession. The features of the most important (actual) problematic situations with which students in sciences and humanities refer are shown. The relation between the readiness for work with a professional psychologist and the age, sex and the faculty of the student is discovered.

\title{
2182
}

\author{
"Naked genes" as health innovation: a challenge for psychological \\ research \\ Nadia Rania*, L. Migliorini \\ "Departiment of Education Sciences, University of Genoa, c.so podesta, 2, Genova \\ 16128 , Italy
}

The identification of hereditary breast/ovarian cancer predisposing genes enabled the introduction of genetic testing in clinical practice. This created new psychological scenarios related to the many choices these women face. To explore the psychological effects of BRCA $1 / 2$ test on ltalian healthy women, the following themes were investigated: childbearing intentions, feelings about the future and future projects, family support, feelings towards children and partners, risk perception, and attitudes towards risk management strategies. The participants were 21 young women (average age 35 years) who had undergone BRCA1/2 testing, recruited from a hospital in a medium city in northwestern Italy. A qualitative approach was chosen to explore these complex and sensitive issues. In depth interviews were developed after a review of the literature. The interviews were transcribed verbatim and were analysed using NVivog. The analysis of the interviews highlighted overall good adjustment to the test results. However, some women underlined a need for long-term psychological support. The main issues were: awareness of psychological support, managing 
uncertainty, impact on life planning, childbearing intentions, and choice of prophylactic surgery interventions. These results may enable better understanding of the experiences of Italian women who underwent BRCA $1 / 2$ testing in order to develop effective interventions in the area of support and care.

\section{7}

The value of participatory visual methods in young masculinity research

David Blackbeard* \& Graham Lindegger

"School of Applied Human Sciences, University of KwaZulu-Natal, Pietermaritzburg, 3201 , South Africa

We discuss the value of visual research methods for empowering participation and dialogue in researching young masculinity. The purpose is to review the benefits and limitations of participatory visual methods in young masculinity research to better understand the construction of masculine identity in context. The discussion is illustrated with reference to examples from completed research projects in young masculinity conducted by the reviewers and which used various participatory visual research methods. These methods included autophotography, photo-elicitation, biographical drawings and combining visual methods with individual interviews or focus groups. Examples from the completed research demonstrate the usefulness of participatory visual research methods in facilitating opportunities for collaborative, contextual and credible qualitative data. The examples from the completed research were used to highlight the value of participatory visual methods and some of the challenges in analysing complex multi-source data, the additional resources required and the practical demands of participatory visual research. Participatory visual research provide innovative opportunities for researching youth identities by facilitating perspectives on the dialogical and dynamic processes of identity positioning within spatio-temporal contexts.

\section{5}

Integrated Motivational Interviewing with Brief Strategic Therapy for Heart patients

Giada Pietrabissa*

"San Giuseppe Hospital, IRCCS Istituto Auxologico Italiano, Italy

Problem Statement: Psychological distress, obesity and unhealthy lifestyles may contribute to a worse prognosis of cardiac diseases an important Public Health challenge is to motivate people and facilitate health behavior change. Research Questions: Specifically, aim of the current study is to test the mediating effect

$1^{\text {st }}-4^{\text {th }}$ December, Limak Lara Hotel, Convention Centre, Antalya/TURKEY 
of motivation in improving lifestyle changes in a long term. Purpose of the Study: The MOTIV-HEART (MOTivational strategies for HEART patients) study, a two-arm randomized controlled clinical trial, compares the efficacy of an alternative-integrative brief motivational intervention (MI) with the cardiac rehabilitation programmed treatment - Brief Strategic Therapy (BST) in order to develop interventions able to improve lifestyle change among heart patients Research Methods: Inpatients with CAD referred to a single clinical center for cardiac rehabilitation (CR) and weight loss treatment will be randomly allocated into two conditions: a) 3 sessions BST, b) 3 sessions of BST plus 1 session of Motivational Interviewing. Data are going to be collected at baseline, discharge ( 1 month after) and after 3, 6, 12 months follow-up. Findings: Three kinds of outcomes are going to be relieved: behavioral, psychological and biomedical. Primary outcome is the improvement of patients diet and physical activity at 3 months follow-up. Secondary outcomes are (a) the maintenance of healthy lifestyle habits, (b) the reduction of patients' body mass index (BMI) and specific cardiac parameters levels, (c) the improvement of adequate psychological outcomes. Conclusions: Obese patients with cardiovascular diseases face numerous difficulties in achieving self-care. Motivational interviewing showed encouraging results in eliciting adoption of high-risk behavioral change, such as initiating an exercise regimen and changing diet. The rationale behind this investigation is that focusing on enhancing motivation would result in better outcomes than those brought about by existing therapy. Study is currently ongoing.

\section{5}

\section{Family Life Space (FLS): Emerging Couple Bonds}

Marialuisa Gennari ${ }^{*}$, Giancarlo Tamanza' Monica Accordini

*Università Cattolica S.Cuore, V.Trieste 17, 25100, Brescia, Italy

International literature hasn't underline enough role and function of couple in migration, although migration in ltaly is a "family matter" that require a great involvement of the marital couple. How do immigrant couples ménage autonomy and freedom and the possibility of setting new and personal objectives, and at the same time deal with ambiguity, uncertainty and loneliness? The aim of the research is to explore the modalities of being and establishing a couple in a foreign land while investigating those factors and variables that, according to the literature on the topic, have proven to be crucial in determining and shaping the migration process. 33 immigrant couples from Morocco, Pakistan and the Philippines were administered Family Life Space, a qualitative graphic instrument useful in the clinical assessment and research with couples that allows to 
overcome linguistic barriers as well as to explore relational dynamics and interactive patterns underlying couple functioning. A k-means cluster analysis allowed the identification of five clusters. The variables considered play a significant role in the cluster formation in particular nationality and the fact of being able to connect the life in the hosting country to that in the country of origin significantly determine the grouping. Future transformations and projects and a "psychological couple center" are other important variables in the cluster formation. The FLS might be particularly helpful in identifying the stage the couple or family considered is going through in their immigration process as well as the possible problems family members might face during their journey towards integration. Lastly, the FLS proves to be a valuable and culture fair instrument with immigrants in both the research and the clinical setting.

\section{1}

\section{Health Care Access - Case of Slovakia}

Jana Levicka* \& Katarina Levicka

*Department of Social Work, Trnava University in Trnava, Slovakia

Problem Statement: In Slovakia, people have a constitutional right to health care, the citizens have to be compulsory health insured. Despite of this fact, healt care is becoming inaccessible for many. Research Questions: What is the actual availability of healt care in slovakia, which areas of healt care access are the most problematic? Purpose of the study: Reveal the most problematic areas in provision and access of health care in slovakia. Discuss the potential impact that impeded access brings. Research Methods: The quantitative research strategy was used. Data were collected through questionnaires focused on various areas of health care access - e.g. financial access, physical access, informational access, nondiscrimination. Findings: Econimic access to health care is proving to be the biggest problem. Paymants for drugs and several devices are so econoimcally burdening that many people often can not afford them. Another problem is centralization of specialist in larger cities. Also perceived as serious problem is waintin time for specilist examination and procedures. Conclusions: Triangle availability - quality - costs must be balanced. Focusing on just one aspect is resulting in imbalance. This can cause economic unsustainability of system, long waiting list and poor quality of provided health care. Problems associated with the avaliability of healt care is affecting ever greater part of population of slovakia. It is necessary to find adeqate solutions.

\section{8}

Counselling network ties of Polish emigrants in the UK Aneta Slowik*

*University of Lower Silesia, Poland 
Problem Statement: Types of migration networks established by Polish emigrants. These distinctions are founded upon the counselling practice within these networks, with a view to their formal, paraprofessional and informal structure. Research Questions: How the helping process within the framework of widely understood support of emigrants (formal, paraprofessional and informal counselling activities), is organised in Polish migration network ties? Purpose of the Study: I will show the institutional and non-institutional counselling activities performed by the Polish emigrants and by some representatives of supporting institutions in the hosting country. I will describe the lack of security resulting from belonging to such networks, while paying attention to manipulative counseling activities Research Methods: I carried out 26 biographical interviews with Polish emigrants living in the area of Newcastle upon Tyne (UK) Findings: The counsellees that do not know the language of the country of the hosting culture, mostly search support in paraprofessional, emigration fields and counselling networks. The pseudo-experts from the emigration community know very well about their needs and difficulties. Having a lot of experience as emigrants, the latter know in detail the mechanisms, stages, traps, to which emigrants are exposed Conclusions: Within my presentation I will show some implications of culture infused counselling: to organize well prepared ethnic community centers whose counselling activities are supervised and to advertise professional counselling services in order to prevent emigrants from counseling activities, which lead to exclusion, marginalization, passivity, apathy, and even being involved in criminal activity

\section{9}

\section{Symbols of healing and transformation in analytical psychotherapy:} The bridge Mihaela Minulescu*

"National School of Administrative and Political Studies, Strada Povernei nr. 6, Sector 1, București, 010643 , România

Problem statement: In association with C. G. Jung constructive and synthetic approach of the psychic dynamics in psychotherapy, there is the need to identify vivid symbols of actual transformation process. Research questions: How, when and in which form such a symbol appears in the analytical process? Purpose of the study: Jung considers transcendent function the connecting principle of the psyche; we concentrate on the significance of The Bridge as a symbolic carrier of the mediation. We want to learn if the Bridge symbol, in the healing process, dream/drawing/sandplay images, appears in the transition periods announcing 
the healing. Jung considers transcendent function the connecting principle of the psyche; we concentrate on the significance of The Bridge as a symbolic carrier of the mediation. We want to learn if the Bridge symbol, gradually visible in the the healing process, by dream/drawing/sandplay images, appears in the transition periods announcing the healing. Methods: The preliminary step: An inquiry on the appearance of The Bridge symbol and its actual meaning in the practice of 40 psychotherapists. The 4 case studies developed in the paper are focused on the gradual introduction and development of "The Bridges" in traumatized children and adults patients. These cases are interpreted in detail, regarding the announcement of the healing process. Findings and results The Bridge conveys multifaceted meanings: Connectedness, orienting towards, crossings over, the danger of falling down, the possible assimilation of the trauma by recognition and tolerance of the opposites which may be followed by a transformation in the psyche. It acts as a potential for realizing a connection and a virtual integration. Sometimes, announces the impossibility to attain the integration. Conclusion: The value of using the bridge as a tool metaphor and the bridge role of the analytical psychotherapist psyche are the major conclusions discussed in the paper.

\section{0}

\section{Teachers in Distress: Counselling Needs of Secondary Teachers in}

\section{Roumania}

\section{Petru Lisievici*}

"Spiru Haret University, Department of Psychology and Education Sciences Braşov, 5-7 Turnului, Braşov 500152 , Romania

Focusing counselling on students in educational environments may seem both justified and consistent with frequently cited paradigms. However, at least in Romania, there is a growing consensus that teachers are being deprived of proper counselling and that something should be done about it. The study analyses current professional and social contexts influencing teachers and identifies counselling needs, using the Lifeskills helping conceptual framework.

The Lifeskills helping conceptual and operational framework proved to be a useful tool for defining counselling needs in such a way as to increase the probability to set up relevant counselling programs targeting specific groups of teachers, as well as to select appropriate intervention techniques and means for individual problems. 


\section{9}

\section{Subcultural Narratives of Pediatric Chronic Illness in the Arab Community}

Azhar Abu Ali* and Nisrine K. Aboul-Hosn

*Latifa Hospital, Dubai Health Authority, Dubai, United Arab Emirates

The experience of pediatric populations and their families with chronic illness and overall health conditions, involves multiple variables. This paper will explore the dynamics of such variables, particularly as it pertains to the Gulf region of the Arab population. Preexisting research demonstrates the multifaceted dimensions of pediatric illness as it impacts acceptance, compliance, and overall coping and quality of life. Within the Gulf community, it is imperative to integrate the complex nature of the family unit into treatment planning and management including gender and familial roles, and overall familial processes and dynamics. Cultural and spiritual perceptions of childhood development and illness also impart a role in adaptive coping and mediate ethical considerations within the sub-context of communication and decision making. Implications for the role of the mental health care professional and future research will also be overviewed.

\section{2}

\section{Minority ethnic identity and discrimination experience in a context of social transformations}

Asta Zbarauskaite ${ }^{*}$, Neringa Grigutyté, Danute Gailienè *Vilnius University, Universiteto g. 9/1, Vilnius, LT-01513, Lithuania

Social transformation is always a diverse and ubiquitous process. In Lithuania social changes were related with gaining independence after a long period of occupation, when a lot of people experienced various traumatic events. Changes in the social context raises a lot of questions about ethnic identities, particularly in minority groups. These people experience various challenges: change of national language, political views and sometimes have to cope with discrimination experience as well. To explore these themes we conducted qualitative research. Objective: to analyse how minority groups reveal their ethnic identity, experience and cope with ethnic discrimination in the context of 
social transformations. Research participants: 60 Lithuanian citizens from ethnic minority groups: 30 participants of Jewish nationality and 30 of Polish nationality. Research methods: Semi-structured interview: 10 main open questions about ethnic identity, discrimination experience in context of social transformations. Thematic analysis was used for narrative data analysis. Results: Social transformations brought more freedom, particularly freedom to speak. With that minority groups claim that in independent Lithuania they experience more open discrimination mostly from politics and anonymous comments on the Internet. Polish minority participants tend to show their ethnic identity, but worry that discrimination can influence their social achievements. Though participants of Jews nationality sometimes fear to reveal their ethnic identity because of threats to health and life. These differences can be related with the experience of historical discrimination.

\title{
2340
}

\author{
Attachment and affection relations in a family: aspects of child \\ attachment \\ Elena Kuftyak \\ *Nekrasov Kostroma State University, 1 May st. 14, Kostroma, 156001, Russia
}

Attachment is valuable for a child for purposes of security and self-preservation, his future behavior and socialization. Our research, conducted in the framework of inter-generational transmission of individual's relations system, investigates the co-relation between indicators of attachment and affection of mothers and grandmothers and child's attachment to his mother. The study involved 30 triads (child - mother - grandmother). The results revealed that mothers' and grandmothers' confidence in significant person's responsiveness and reliability is connected with child's emotional sensitivity increase. The results indicate the joint behavior strategy in "mother /close adult-child" system which is necessary to consider in professional work.

\section{3}

\section{Social physique anxiety and it's relation with body dysmorphic} disorder

Dr.Mehryar Nader Mohammadi, Ehsan Assadollahi, Maede Niazifar*

"M.Sc. of Clinical Psychology, Psychiatry Department of Yahyanezhad Hospital, Modares Street,Babol,4713655647,Iran,Tel:011-32223594,fax:011-2225035

Purpose of study: The current study has been performed in order to compare social physique anxiety and Body Dismorphic Disorder between a group under medical cosmetic treatments and a control group. Methods: The study population consisted of 200 subjects, undergoing medical cosmetic therapy and 200 not

$1^{\text {st }}-4^{\text {th }}$ December, Limak Lara Hotel, Convention Centre, Antalya/TURKEY 
receiving any medication considering this matter, which were selected by handto-hand and simple random sampling. In this post-causal study, to gather the information required for Heart's social physical anxiety criterion, Philips' Body Dismorphic Disorder diagnostic questionnaire was distributed amongst the subjects. Findings: A significant difference and opposition, considering the degree of social physical anxiety $(p=0.04)$, the number of persons with Body Dismorphic Disorder $(P=0.05)$ and those who showed a tendency towards cosmetic surgery $(P=01)$, was observed between the main group of subjects and the control group. In both groups, those who had physical disorders, abnormalities or deformities, experienced higher levels of social physique anxiety. This value was reported higher in the subjects of the control group. Conclusion: The results indicate that the subjects of the group which had visited a center in order to receive cosmetic treatments, experience lower levels of social physique anxiety. Having Body dismorphic Disorder and not receiving the required cosmetic treatments and medications, were determined the most important factors in predicting social physical anxiety levels, whilst other attributes, such as gender and the patient's tendency towards undergoing a cosmetic surgery, are not effective in the prediction of such a value.

\section{2}

Mediating Effects of homosexual-specific Social Support in Korean gay Myoung-Ho Hyun, Woon-Sook Jeon, Eun-bin Na, Sue-Hyun Jung, Da-Eun Jeong "Psychology department of Chung-Ang University, Korea, Democratic People's Republic of

Problem Statement: The cultural characteristics of Korean paternalism and heterosexism stigmatize sexual minority. Perceived stigma causes isolation because of avoiding self-disclosure. Therefore it needs to examine the effect of problematic social support. Research Questions: In the process of between perceived stigma and life satisfaction, the homosexual-specific social support has higher mediation effect. The homosexual-specific and general social support have a different effect on coming-out Purpose of the Study: In previous studies, social support was protective factor. but by the special nature of Korean culture, the effect will be different. Therefore this study will examine the effect of problematic social support. Homosexual-specific support will contribute to life satisfaction. and person who received higher in homosexual-specific support will more coming-out Research Methods: To ensure the anonymity of participations, it used online survey and collected 286 gay and lesbian samples. Stigma-perception scale, Internalized Homophobia scale, and Anti-Gay violence scale measured perceived social stigma. Coming-out is measured by Meyer et al. (2002) scale. 
Life satisfaction measured by Psychological Well-Being Scale (1989). Social support scale which is developed by Park (1989) reconstructed to fit homosexual. Findings: Homosexual-specific support score was higher than general social support. General social support was negatively related to coming-out(p.05), and positively related to life satisfaction(p.o1). Homosexual-specific support was positively related to coming-out(p.05), and strong positively related to life satisfaction(p.o1). Indirect effect of Homosexual-specific support on life satisfaction was significant(p.o1). it significantly moderated mediation on coming-out ( .05 ) Conclusions: The purpose of this study was to find protective factor that affect life satisfaction in negative view on homosexual. General social support is associated with Korean familism, and there was a little protective effect. Homosexual-specific support had greater positive effect on life satisfaction, showed greater effect through coming-out. Therefore, this study demonstrated that Homosexual-specific support is protective and its necessity.

\section{9}

\section{Integrated Motivational Interviewing with Brief Strategic Therapy for Heart patients \\ Giada Pietrabissa*, Angela Sorgente, Gianluca Castelnuovo \\ *Istituto Auxologico Italiano IRCCS, Psychology Research Laboratory, Ospedale San \\ Giuseppe, Verbania, Italy}

Problem statement: psychological distress, obesity and unhealthy lifestyles may contribute to a worse prognosis of cardiac diseases; an important public health challenge is to motivate people and facilitate health behavior change.

Research question: specifically, aim of the current study is to test the mediating effect of motivation in improving lifestyle changes in a long term. Purpose of the study: the MOTIV-HEART (MOTivational strategies for HEART patients) study, a two-arm randomized controlled clinical trial, compares the efficacy of an alternative-integrative brief motivational intervention ( $M I$ ) with the cardiac rehabilitation programmed treatment - Brief Strategic Therapy (BST) - in order to develop interventions able to improve lifestyle change among heart patients. Research method: inpatients with Coronary Artery Disease (CAD) referred to a single clinical center for cardiac rehabilitation ( $C R$ ) and weight loss treatment will be randomly allocated into two conditions: a) 3 sessions of BST, b) 3 sessions of BST combined with Motivational Interviewing (MI) techniques. Data are going to be collected at baseline, discharge ( 1 month after) and after $3,6,12$ months follow-up. Finding: three kinds of outcomes are going to be relieved: behavioral, psychological and biomedical. Primary outcome is the improvement of patients' diet and physical activity at 3 months follow-up. Secondary outcomes are (a) the maintenance of healthy lifestyle habits, (b) the reduction of patients' body mass index (BMI) and specific cardiac parameters levels, (c) the improvement of adequate psychological outcomes. Conclusion: obese patients 
with cardiovascular diseases face numerous difficulties in achieving self-care. Motivational interviewing showed encouraging results in eliciting adoption of high-risk behavioral change, such as initiating an exercise regimen and changing diet. The rationale behind this investigation is that focusing on enhancing motivation would result in better outcomes than those brought about by existing therapy. Study is currently ongoing.

\section{0}

\section{The cross-cultural application of the DSM-V}

\section{Jo Thakker*}

"Senior Lecturer, School of Psychology University of Waikato, New Zealand

Problem Statement: How well does the DSM-V take account of the cultural aspects of mental disorder? Research Questions: What are cultural syndromes and what does culturally-approved mean? Purpose of the Study: The purpose of the study is to examine the DSM-V and see to what extent it takes account of cultural variables. It has a section on cultural syndromes and cultural explanations, however, do these make it culturally appropriate? Research Methods: This study involves an analysis of the DSM-V. Each cultural aspect of the manual is analysed to assess it for its cultural sensitivity. Findings: The findings show that the changes are essentially superficial and that the thrust of the manual is culturally insensitive. For example, it is not clear what exactly is a "culturally approved" mental disorder. Also, it is not clear what setting clinicians would use the cultural syndromes. Conclusions: The cultural aspects of the manual are largely insensitive. Suggestions for conducting assessments in a more culturally sensitive way are discussed.

\section{3}

\section{Unexplained anticipatory activity in patients with traumatic brain} injury ( TBI)

Petr Kulistak*

"Charles University in Prague, Faculty of Arts, Dept. of Psychology, Czech Republic

Problem Statement: In patients with TBI localized in the fronto-temporo-parietal area, almost all cognitive functions tend to be disrupted with varying severity. Intuition related behavior may be diversely impacted as well. Research Questions: if any, is there more significant impact of TBI on the level of abstract 
thinking or intuition/anticipatory activity, being two different aspects of cognition? Purpose of the Study: If any, is there more significant impact of TBI on the level of abstract thinking or intuition/anticipatory activity, being two different aspects of cognition? Research Methods: Conventional neuropsychological methods have been used: the Wisconsin Card Sorting Test (WCST) and the lowa Gambling Task (IGT). In order to ascertain procedure and strategy chosen by the subjects, subsequent interviews were conducted, which also included questions on impressions and feelings related to performing the tasks. Findings: The main finding is a significantly worse performance of patients with TBI in the WCST $(p=.001)$, combined with reaching similar results in the IGT, both compared with healthy controls. More interestingly, higher proportion of optimal procedure (i.e., reaching significantly more gains) in patients with TBI than in controls ( $37 \%$ v. $22 \%$ ) was observed. Conclusions: Our findings suggest unaffected intuitive thinking in patients with fronto-temporo-parietal lesioned TBI, which is interpreted by theory of visceral cognition and embodiment. It is assumed that when compared with approach requiring abstract thinking, hypotheses testing and mental flexibility - which is impaired in patients with TBI, their intuitive mechanisms used in solving tasks with unpredictable results remain preserved.

\section{1}

\section{Communication from 'bruises' to Ipad} Ann-Katrin Sward*

*Gothenburg University, Sweden

Problem Statement: New research has shown the importance of using new technology when individuals have difficulties with communication, in this case autism spectrum disorder in combination with intellectual disability. Research Questions: How was the process of transition from earlier communication to the introduction of lpad and in what way has the use of Ipad improved communication skills? Purpose of the Study: The aim of the study was to investigate what one family has done over the year to increase their daughter's communication skills. Research Methods: A retrospective case study was carried out through interviews and observation. The interviews to recall the process of the family's communication support from their daughters early years to adult and observation for having a picture of today's communication. A retrospective case study in which different empirical data was collected and used to recreate one process of development or change. Findings: The results show that communication skills increased when lpad was introduced but earlier efforts to work with picture was also of importance. The Ipad gives a voice to the picture and makes the communication more verbally and interesting. It also gives more independent opportunities to choose your communication by select different topics and easy to carry with you. Conclusions: When individuals have limited ability to communicate like when having diagnoses within autism spectrum new 
technology like Ipad seems to be useful. It gives the person many options to communicate and be more independent. It also gives possibilities to participate and be more active in different context and situations. Perhaps strengthen your self-image as a communicative person.

\section{3}

\section{Contributions to the quality of life of chronic renal insufficient} Conceição Martins*, João Duarte \& Claudia Chaves

"Superior Health School, Polytechnic Institute of Viseu, Rua D. João Crisóstomo Gomes de Almeida, $n^{0} 102$, 3500-843 Viseu, Portugal, Phone +351232419100, Fax $+351232428343$

Introduction: Quality of Life of renal insufficient patients cannot be evaluated only on a partial basis, but rather as whole human beings, with their individuality, particularly in their health, social and economic, psychological, emotional, familial and environmental status. Our aim: to assess the quality of life of haemodialysis patients in their variable contexts such as, personal, sociological, physiological, social and emotional lives. Methods: A crosssectional study was conducted in 4 treatment units in the centre of Portugal. Data collection was carried out by questionnaire divided into various scales and applied to 160 haemodialysis patients. Results: Age, overall anxiety and extroversion are predictive factors of physical functions. Social-economic levels, age anxiety and extroversion are relative physical functions. Cognitive anxiety, haemodialysis time, age and a sense of responsibility/demand are predictors of pain. Somatic anxiety, duration of haemodialysis, extroversion and financial support are predictors. Extroversion, cognitive anxiety, age, and total social support are predictors of vitality. Total social support, family Apgar, age and somatic anxiety are predictors of social functions. Social-economical levels, age and physiological performance. Neurological stability is the only predictor of mental health. Age and overall anxiety predicted health changes. Socialeconomical levels, cognitive anxiety, age and extroversion were general predictors of overall quality of life. Conclusions: We would like to point out through these results, the importance this type of research, in that it has given some contribution to the quality of life of haemodialysis patients.

\section{1}

The Study Of Relationship Between Attachment Styles and Obsessive Love Style 
Bahareh Honari*, Ali Akbar Saremi

*Department of psychology, Islamic Azad University, Ghochan - branch, Iran

The aim of this study was investigating the relationship between the attachment styles and obsessive love style of university students. The samples included 306 graduate students University of Nyshaboor-Iran that were selected with proportional random assignment procedure. The data were collected by using Adult Attachment Style (AAQ) and Love Attitude Style (LAS) Questionnaires. By employing SPSS software, the data were analyzed by using Pearson correlation coefficient and Multiple Variable Regression procedures. Therefore we can conclude that the Ambivalent Insecure Attachment Style has a role in producing obsessive Love Style. The results of different analysis showed significant relationship among Obsessive love Style and Attachment Styles.

\section{5}

Neuropsychological functioning in Obsessive-Compulsive washers

Ali Akbar Saremi*, Seyed Vahid Shariat, Mohammad Ali Nazari, Behrooz Dolatshahi

*Iran (Islamic Republic of)

Problem Statement: Obsessive-compulsive disorder is a chronic and debilitating neuropsychiatric disorder. OCD is clinically heterogeneous. The contamination/washing subtype (contamination obsessions with cleaning/washing compulsions) is one of the most frequent OCD subtypes. Research Questions: OCD is associated with impairments in multiple neuropsychological domains but the findings are rather inconsistent across studies. Purpose of the Study: The aim of the present study was to compare neuropsychological test performance in OCD patients and healthy controls. Research Methods: Thirty- Five DSM-IV-diagnosed OCD (contamination/washing type), and 35 healthy individuals (control group) were evaluated with clinical and Neuropsychological Tests : Stroop Color Word Test, Wisconsin Card Sorting Test, Go _ No Go Task, digits forward (DF), digits backward (DB), Yale Brown Obsessive - Compulsive Scale, Beck Depression Inventory, Beck Anxiety Inventory and Frontal Lobe Personality Scale. Findings: OCD did not differ from the control group on sociodemographic variables or IQ. There were significant differences between OCD patients and the non-patient comparison group on neuropsychological functioning.OCD Patients performed poorly on all the neurocognitive parameters as compared to controls. The difference between the OCD group and the normal control group was significant in clinical tests. Conclusions: The results suggest that OCD patients perform significantly worse on cognitive measures than controls. We conclude that executive impairment is a core feature in OCD. Future studies are needed to confirm our findings.

$1^{\text {st }}-4^{\text {th }}$ December, Limak Lara Hotel, Convention Centre, Antalya/TURKEY 


\section{2}

\section{The impact of brain injury on emotional intelligence}

M. Noor Rochman Hadjam* \& Lu'luatul Chizanah

*Faculty of Psychology, Universitas Gadjah Mada, Yogyakarta 55283 , Indonesia

In this study, the effect of traumatic brain injury to the emotional intelligence was examined. It was identified by testing the difference of emotional intelligence among (1) types of injury (traumatic brain injury-non traumatic brain injury), (2) injured area of brain, (3) level of traumatic brain injury, and (4) injured area and level of brain injury. The participants in this study were twenty. They were asked to fill the emotional intelligence scale designed by the researcher. The data obtained was analyzed using non-parametric approach. The results showed there was significant effect of traumatic brain injury to the emotional intelligence $(Z=-2.546 ; p<0.05)$. Meanwhile, there was no significant effect found to the emotional intelligence among the injured area of brain (chisquare=1.107; $p>0.05)$, level of brain injury $(Z=-1.226 ; p>0.05)$, and both; the injured area and the level of brain injury $(F=0.302 ; p>0.05)$.

\section{3}

\section{HOPE: Depression Intervension in Merapi Cold Lava Survivors}

Sofia Retnowati ${ }^{*}$, Diah Windy, Ramadhiyanti, Azri Augustin Suciati, Yasinta Astin Sokang, Halda Viola

*Gadjah Mada University, Indonesia

Problem Statement: The stress that volcano survivors experienced was not only physical distress, but also psychological distress, namely anxiety and depression Research Questions: Does HOPE, in which consists of four sessions therapy that aimed subject to identify goals, strategy planning, and increasing motivation can be an effective one to reducing depression symptoms? Purpose of the Study: To examine HOPE therapy in reducing depression symptom among Merapi volcano survivors Research Methods: Quasy-experimental to test whether or not HOPE can be an effective intervention. Design of experiment was untreated control group design with dependent pretest and posttest. Findings: There was a significant difference in depression scale score between the $1^{\text {st }}-4^{\text {th }}$ December, Limak Lara Hotel, Convention Centre, Antalya/TURKEY 
experimental and control groups, before (pre-test) and after (post-test) intervention $(F=11.589, p 0.05)$. Conclusions: HOPE is an effective intervention in decreasing depression among Merapi's cold lava flow survivors.

\section{6}

\section{Internet supported Cognitive Behavior Therapy to help students with} shy-socially isolated problems

Neila Ramdhani*, Jeanita Deli Widjaja

*Gadjah Mada University, Indonesia

Problem Statement: Increasing the use of computer among adolescent may reduce skills to build social relationship. Internet supported CBT may need to be developed to help students who face shy-socially isolated problems Research Questions: Does the Internet supported Cognitive Behavior Therapy can be an alternative to help adolescent with shy-socially isolated problems. Purpose of the Study: To test role of the Internet in helping adolescent who face shysocially isolated problems. Firstly, the Internet supported CBT has been applied to reduce social anxiety among shy-isolated adolescent. Secondly, the Internet also applied to support self management technique in changing cognitive distortion among adolescent. Research Methods: This study was applied mixed design that combine repeated measures and independent designs. The Social Anxiety Scale and Cognition Distortion Scale have been used in pre-post treatment. In order to enrich the data of behavior changing in detail, two psychologists observed and rated subject behavior during the experimental processes. These data are analyze using ANOVA and Visual Inspection Findings: It shows that the Internet supported self-management training is effective to decrease cognitive distortion in depressed adolescent ( $F=8,363$ po,1). The same result also in the role of Internet supported CBT to reducing social anxiety. There was an interaction between time of treatment and group $(\mathrm{F}=5.063 \mathrm{p}=$ 0.026 Conclusions: The Internet can be used to support psychological treatment, especially in CBT and self management technique.

\section{2}

\section{Structured peer group supervision: Utility and benefits} Jacqueline Akhurst*

"York St John University, United Kingdom

Problem Statement: Though peer group supervision is widely used by counsellors and psychotherapists, there is limited research evidence about group structure, the participants' experiences of the process and its utility. Research Questions: How do group members respond to a structured model of peer group supervision and what is the utility of peer group supervision? Purpose of the Study: To trial 
and develop a model of peer group supervision, designed to provide structure and where participants take a solution-focused case-based approach. The study investigated the experiences of the model with groups of psychologists, counsellors and other health professionals in the UK and South Africa. Research Methods: Interviews, focus groups and an on-line survey were used to gather experiential data and feedback. Thematic analysis (Braun \& Clarke, 20o6) was used to synthesise the findings. Findings: Excerpts will be shown from the DVD demonstrating the PGS model. This model was found to provide a safe space where participants explore their experiences and provide constructive feedback. It encouraged reflection on experiences and a supportive space, affirming participants for existing skills/knowledge and enabling them to share expertise it built their confidence and problem-solving abilities. Conclusions: The PGS model shows clear benefits due to its structure and the approach can be applied across a variety of settings in the helping professions. It has the potential to effectively complement traditional supervision, to build practitioner autonomy and provide input on the complexity of casework from diverse perspectives.

\section{9}

\section{Health beliefs about cervical cancer in university students}

Paula Nelas*, João Duarte, Cláudia Chaves, Emília Coutinho, Odete Amaral

"Superior Health School, Polytechnic Institute of Viseu, Rua D. João Crisóstomo Gomes de Almeida, no $102,3500-843$ Viseu, Portugal

Problem Statement: Exist in Europe about 60000 women with cervical cancer and of these, 30000 die annually. Through screening programs we can prevent many cases of illness and death (ECCA, 2013) Research Questions: What are the health beliefs about cervical cancer in university students? Purpose of the Study: Identify health beliefs about cervical cancer in university students. Research Methods: This is a quantitative, analytical, comparative and correlational study, with a sample of 345 university students. The data collection instrument is a questionnaire that assesses the health beliefs about cervical cancer in university students and the Health Belief Scale (Patrão, 2000) Findings: The participants have a low belief in vulnerability, an average belief of gravity relative to the cervical cancer, a high belief in benefits and indifference on belief of barriers to screening. Conclusions: Health professionals are fundamental in health education so people adopt healthy attitudes to health, to encourage adherence to screening for cervical cancer and demystify wrong ideals. 
2572

Validation of "Schwartz Values Scale" for spanish adolescents

J. Paez \& A. De-Juanas*

*Universidad Nacional de Educación a Distancia (UNED), Juan del Rosal st., 14, Madrid 28040 , Spain

The Schwartz value scale (SVS) has shown strong potential in assessing the value system modeled on Universal Values Schwartz in different cultures and populations. But it is necessary to know if the "SvS" meets the psychometric characteristics necessary to assess the value system of population of different ages. The objective of this research is to understand the potential of svs to assess adolescents axiological system. For validation of the scale has been used an incidental sample comprised 1262 adolescents of both sexes aged between 12 and 22 years old from 14 Spanish secondary schools. The reliability of the adaptation of "SVS" for spanish adolescents shows a high internal consistency of the items (Cronbach's alpha =, 892). However, the reliability of various subscales are lower than those established in the interpretation criteria. The adaptation of the Schwartz Values Scale for adolescents spanish population allow assess with high reliability and validity the value system of adolescents.

In addition, the subscales obtained with the ten factors allow individually measure each of the ten values Schwartz model.

\section{9}

\section{Does moral emotion plays role in cyber-bullying?}

Arini Sasikirono Suparli*, Neila Ramdhani

*Gadjah Mada University, Indonesia

Problem Statement: Number of cyber-bullying among the Internet user has been increased. People can posted unusual act and words to express their negative feelings in the cyber-world. Research Questions: Does any of emotion moral, for example shame, guilt, detached have correlation with cyber-bullying? Purpose of the Study: Purpose of this study is to find out which emotion morales most play role in cyber-bullying among adolescent. Research Methods: A survey had been carried out to collect both emotion morale and cyber-bullying data. Eighty senior high-school students, 41 females and 39 males participated in this study. Data analyzed using a simple correlation. Findings: It was found that shame (mean= 34.23) and externalization (mean=35.75) are higher compare with guilt (mean=19.71), detached (mean=19.72), alpha-pride (mean=9.31), and beta-pride 
(mean=9.81). All aspects of morale emotions negatively correlated with cyberbullying. Beta-pride is the lowest $(r=.27)$ while externalization is the highest $(r=-.48)$ correlation with cyber-bullying. Conclusions: Emotion morals plays important role towards cyber-bullying. Each aspect of emotion morals will be discussed further.

\section{3}

\section{Cognitive-behavioral therapy of patients with PTSD Ivanna Shubina* \\ *American University of Middle East, Kuwait}

Exposure therapy was the first one, which effectiveness was proved in psychological treatment of posttraumatic stress disorder (PTSD). However, studies have shown that this therapy was appropriate for some patients with PTSD, what caused the development of other models and therapies, among which the most important and effective are the theories of information processing and emotional processing. Studies have proved that cognitive-behavioral therapy ( CBT) effectively reduces PTSD symptoms and accompanying depression, anxiety, giving similar results. CBT is a short-term therapy, and the achieved results are maintained afterwards. The main purpose of the PTSD cognitive-behavioral therapy is to reduce discomfort and improve the patient life. According to the authors of contemporary models of PTSD cognitive therapy, the patients' emotional involvement in traumatic memories makes a distorted cognitive content accessible and creates a base for its modification, using a combination of cognitive and behavioral techniques to help patients identify and modify distorted beliefs connected with PTSD. Lack of knowledge about change mechanisms, the most responsive to therapy symptoms, do not let to answer the question - whether PTSD cognitive-behavioral therapy will be the therapy of future. It depends on the fact if the current research results will help develop effective PTSD therapies methods. This presentation provides an overview of basic concepts, application principles, and research results on the effectiveness of PTSD cognitive-behavioral therapy.

\section{7}

Self-harming behavior and its relation to previous psychological or psychiatric care

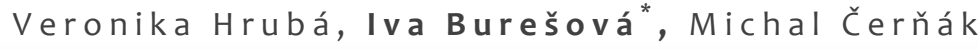


*Institute of Psychology, Faculty of Arts, Masaryk University, Czech Republic

The study was realized in cooperation with grant support: MUNI/A/0790/2012 "Verifying the psychometric properties of diagnostic tools for screening the incidence and forms of self-harm among school children". This study explores self-harming behavior among adolescents (12-15 years old) and its relation with previous psychological or psychiatric care. There is a connection to the process occurrence type of self-harm between adolescents who have been or are in psychological or psychiatric care and those who were never been. The results can spread our knowledge about self-harm behavior, which is very common teenage phenomenon. Furthermore, it can be used to specify the support for adolescents who do self-harm. In accordance with the research objectives were quantitative, exploratory data, in a one-shot cross-sectional survey using self-report measures. Our sample was 1110 adolescents between 12 to 15 years old. In our sample were 84 adolescents who do or did self-harm. The methods for measuring self-harm included the Self-Harm Inventory (SHI; Sansone, Sansone, \& Wiederman, 1995). The main differences were found in occurrence of self-harm behavior between children who have never been in psychological or psychiatric care $(20 \%)$ and the others (40\%). Small differences were found also in different type of self-harm behavior. On the other hand we did not find differences in the self-harm process. There are differences between those adolescents who have never been in psychological or psychiatric care and the others. We hope that the results of this study could help to understand the self-harming behavior, which is currently spreading among adolescents. It could be a useful guide for those, who are working with the youth.

\section{8}

\section{Learning strategies and academic performance}

Alvaro Muelas*, Enrique Navarro

*Universidad Internacional de La Rioja (UNIR), Spain

Problem Statement: Currently, there is a social concern about the low academic achievement of students 12 . Neuropsychology may be a way to help them improve their academic performance. Research Questions: Does the use of neuropsychology and learning strategies will improve the academic performance of students 12 years? Purpose of the Study: To determine whether the use of learning strategies by students improve their academic performance. It is therefore essential that the lobes frontal, occipital, parietal, temporal, and are active and stimulated by the student. Research Methods: The research method that will take place is not experimental and correlational because they purport to measure and accurately assess the degree of relationship between two variables (learning strategies and academic performance) in a group of subjects. The correlation can be positive or negative and requires the presentation of hypotheses to be tested. Findings: Through this study, it is found as learning strategies in relation to neuropsychology, specifically variables acquisition,

$1^{\text {st }}-4^{\text {th }}$ December, Limak Lara Hotel, Convention Centre, Antalya/TURKEY 
encoding, retrieval, and information support, influence academic performance of students in subjects such as language arts, math and social studies, geography and history. Conclusions: Taking into account the objectives, hypotheses and research results, the conclusions that come are learning strategies that partially correlate with the Academic Performance of students in the subjects of language, mathematics and social sciences, geography and history while not correlate with the English class.

\section{2}

\section{Mediating-effect of Narrative-Identity and Self-Esteem in relationship between Self-Focused Attention and Depression}

Jongeun Lee*, Eunjoo Yang

"Department of Psychology, Korea University, Korea, Republic of

Problem Statement: Self-focused attention is related to the deveplopment and maintenance of depression. Two aspects of self-directed attention, rumination and reflective pondering have a distinctive association with depression. Research Questions: It was hypothesized that rumination might lead to greater depression via lowering self-esteem, yet reflective pondering might be associated with lowered depression via a higher level of identity. Purpose of the Study: The main purpose of this study was to investigate the mediating effects of narrative identity and self-esteem in the relationship between self-focused attention and depression with a sample of 1813 adults. Research Methods: Participants in this study were 1813 adults, 925 males ( $51 \%$ ) and 888 females ( $49 \%$ ). The recruit of participants and online data collection was done by a private survey company. The structural equation modeling was used in this study. The measures of rumination, reflective pondering, self-esteem, and depression were unidimensional, thus, item-parceling was used as measurement variables. Findings: Self-esteem mediated the relationships between rumination and depression and between reflective pondering and depression. Narrative identity mediated only the relationship between reflective pondering and depression. In addition, rumination predicted depression directly, while reflective pondering did not. Conclusions: Both narrative identity and self-esteem served as mediators in the relationship between self-focused attention and depression. Rumination may lower one's self-worth by focusing on negative self characteristics, while reflective pondering may contribute to improving self-worth by helping one to regulate negative emotions toward self. Narrative identity is facilitated by reflective pondering, as it may improve self-awareness and insight. 


\title{
2643
}

\author{
Self-esteem and hopelessness as predictors of emotional difficulties \\ among adolescents in Kosovo \\ Naim Fanaj", Erika Melonashi, Fleura Shkëmbi \\ *Bulevardi "Gjergj Fishta"Nd.70, H.1, 1023, Tirana;+37744192053
}

The growing prevalence of emotional difficulties among adolescents represents an important public health issue for several countries, especially those with relatively young population such as Kosovo. The main research question of the present study is whether self-esteem and hopelessness are significant predictors of emotional difficulties among adolescents in Kosovo. The purpose of the study was to investigate the level of emotional difficulties among adolescents in Kosovo and determine whether self-esteem and hopelessness serve as significant predictors of these difficulties. Participants were 1162 adolescents aged between 11 and 20 years old $(M=16.37$; $S D=1.58)$; in terms of gender composition, there were girls $593(51 \%)$, boys $535(46 \%)$. The measures used included the Albanian versions of The Strengths and Difficulties Questionnaire (Goodman,1997), Rosenberg Self-Esteem Scale (Rosenberg,1965) and the Hopelessness scale for children (Kazdin et al, 1986). Results indicated that $16.3 \%$ of participants reported abnormal levels of emotional difficulties, $52.7 \%$ reported low selfesteem and $19.6 \%$ reported high hopelessness levels. Emotional difficulties were significantly predicted by hopelessness $(\beta=.272, p<.00)$, self-esteem $(\beta=.112$, $p<.00)$, gender $(\beta=.258, p<.00)$, and residence $(\beta=.128, p<.00)$. Together these variables explained $17 \%$ of the variance in emotional difficulties. The study found relatively high levels of emotional difficulties especially in mid-adolescence. Findings suggested that self-esteem and hopelessness might partially explain emotional difficulties. Despite the low statistical power of findings it is important to investigate these relationships in future research, especially when considering that more than half the sample reported low self-esteem and almost $1 / 5$ reported high hopelessness.

\section{4}

The Moderating Effect of Age on Relationships of Self-Compasion, Self-Esteem, Mental Health

Soodeok Hwang*, Eunjoo Yang

*Department of Psychology, Korea University, Korea, Republic of 
Problem Statement: Self-compassion is known to exert emotional buffer effect unlike self-esteem. However, it is unclear whether difference between these two concepts on mental health would be observed in all ages. Research Questions: This study intended to find out whether self-compassion and self-esteem independently explain psychological well-being, and if age presumably moderates the influence of self-compassion and self-esteem on mental health. Purpose of the Study: This study primarily aimed to identify the interactive effect of selfcompassion, self-esteem, and age on mental health, strengthening the previous findings addressing seperate influences of self-compassion and self-esteem. The findings will provide practitioners working for welfare of the aged with helpful information for their mental health-enhancing interventions as well. Research Methods: A total of 1,813 adults $(M=39.28$ years, SD $=11.27)$ completed a questionnaire measuring self-compasion, self-esteem, subjective well-being, and depression. The interactive effects among self-compassion, self-esteem, and age on subjective well-being and depression were verified respectively through two independent models. Hierarchical regression analysis was conducted and the regression line was drawn to grasp the interaction. Findings: In both older and younger adults, the higher self -compassion was, the greater subjective wellbeing would be, and slope of the regression line in older age group was significantly steeper(p .01). Self-esteem had negative association with depression in both high and low self-compassion, and the variation of depression depending on self-esteem was greater in low self-compassion group(p .01). Conclusions: Compared with younger adults, self-compassion played a more important role in leading psychological flourish for people in their late life. In case of psychological maladjustment, self-compassion buffered the influence of self-esteem on depression no matter how high or low self-esteem was. So it would be useful especially for older adults to learn to be self-compassionate for their mental health.

\section{5}

Mediating effect of anxiety on relationship between inter-parental conflict and students' self-efficacy

Parisa Parsa*, Nakisa Parsa, Mohammad Ahmad-Panah, Ali Ghaleiha

* Chronic Diseases (home care) Research Centre, Department of Mother and Child Health, Hamadan University of Medical Sciences, Hamadan, Iran

Problem Statement: Despite of importance of self-efficacy in psychological and social well being among adolescent, still numbers of student suffers of low selfefficacy and consequently low academic performance. Research Questions: What factors are associate with self-efficacy among adolescent students.. Purpose of

$1^{\text {st }}-4^{\text {th }}$ December, Limak Lara Hotel, Convention Centre, Antalya/TURKEY 
the Study: This study aims to determine the relationships between inter-parental conflict, anxiety to perform social skill and self-efficacy among late adolescent students in Hamadan University of Medical Sciences, Iran. Research Methods: This quantitative study used a correlation research design. Participants were 374 randomly selected collage students aged between 17-19 years old. Selfadministered questionnaire were used to collect data. Instruments consist of General Self-Efficacy Scale, The Children's Perception of Inter-parental Conflict Scale, Scale for Interpersonal Behavior. Descriptive, bi-variate and multivariate statistics were used in data analysis. Findings: Pearson's correlation analysis showed that perception of inter-parental conflict and anxiety to perform social skill were negatively related to adolescent's self-efficacy (po.05). The result of study also shows that anxiety to performance of social skill partially mediates the relationships between inter-parental conflict with self-efficacy among respondents. Conclusions: The result of this study highlighted the importance of maternal and paternal factors in enhancing self-efficacy among late adolescent students. The nature of anxiety to perform social skill as a mediator implied that self-efficacy of adolescents can be improved if parent-adolescent relationships be improved and adolescent do not experience insecurity and anxiety.

\section{3}

\section{The Authoritative Syndrome in Attitudes and Educational Practices of Russian Parents \\ Olga Bezrukova*, Valentina Samoylova \\ "Saint-Petersburg State University, Department of Sociology, Saint-Petersburg, 191124 , Russian Federation}

In the structure of indicators of authoritarianism, a central position is occupied by rigidity of educational attitudes as a manifestation of the syndrome of authoritarian aggression. This article addresses educational attitudes of mothers, as well as their idea of the role of a father in families with varied economic resources. The study involved 500 mothers, selected basing on the criterion of self-identification of their economic status (low and medium), under the age of 45 , with children aged from 1.5 to 3 years old. Educational attitudes were estimated on the basis of views characterizing typical principals of upbringing of children in everyday family life. This study highlighted that authoritarian attitudes are characteristic of low resource families, rather than of families with medium resources. A similar tendency can be traced in mothers' perception of fathers in these families: as more authoritarian and more democratic, sensitive, partner-oriented in communication with their children, respectively. This work suggests the directions in correction of authoritarian educational attitudes.

$1^{\text {st }}-4^{\text {th }}$ December, Limak Lara Hotel, Convention Centre, Antalya/TURKEY 


\section{5}

\section{Dating... making out... Young girls' relationships experience in the affective-sexual sphere}

Emilia Coutinho, Paula Favas, Joao Duarte*

*Health School of Viseu, CI\&DETS - Polytechnic Institute of Viseu, Portugal,R.. D. João Crisóstomo Gomes de Almeida no $1023500-843$ Viseu, Portugal, Telephone 232419100 , Fax 232428343

Introduction: Human values are consolidated during youth. Attitudes towards sexuality, love, the roles and norms of relationship between the sexes reveal the affective experience as privileged in personal relationships. Research Questions: What is the meaning assigned by young girls to their affective-sexual relationships? What are the feelings experienced by young girls in their affective-sexual relationships? Purpose of the Study: To discern the experiences of young girls in their affective -sexual relationships. Research Methods: Descriptive exploratory study, using a semi-structured phenomenological interview, with a purposive sample of twenty-three young girls. The sample consists of female students, aged from 15 to 24 years, customers of the Youth Sexuality Supporting Bureau, of the Portuguese Youth Institute (IPJ), between February and March 2007. Findings: From the affective-sexual relationships theme the following categories emerged: the meaning of dating, sex as the culmination of sharing, and venturing into unprotected sex. Young girls revealed that despite having friends "with benefits" and making out, when dating was not serious, the need to share feelings, trying to understand the "other" motivated the relations change. Conclusions: Several girls revealed that they would have liked to have more information, and that their "first time" was not up to their expectations. Some assumed the partner had no diseases or risked on unprotected intercourse to feel pleasure, a fact that reveal the need to keep investing in building the sense of a full, safe, rewarding sexuality and reproductive life.

\section{7}

\section{Brain Dynamics of Mild Cognitive Impairment (MCI) from EEG Features} Norsiah Fauzan*, Nur Hurunain Amran *University of Malaysia Sarawak, Malaysia

Problem Statement: Early diagnosis of Alzheimer's disease (AD) and its treatment requires early detection before its progression to dementia. Research Questions: What are the brain dynamics of MCI from EEG features that might display the 
early signs of cognitive decline? Purpose of the Study: The main objective of this research is to identify and analyse the Brain dynamics of MCl from the EEG signal features that will contribute to a better understanding of brain dynamics of $\mathrm{MCl}$ patients Research Methods: ii. i Qeeg recordings ii. 20 participants screened from MMSE ( 14 were considered normal and $6 \mathrm{MCl}$ ) iii . Analysis : z scores were computed from the mean of absolute power ( $u V^{\wedge} 2$ ) from the two groups (Normal vs $M(1)$. Findings: Findings indicates greater beta 2 power in MCl over the frontal region, highest at Fp1 and F 8 with the right predominance at the anterior region .Increasing theta have been reliably associated with AHC atrophy as well as with memory deficits, a major risk for the development of Alzheimers' disease and MCI subjects Conclusions: EEG analysis among the MCI group revealed the increase of beta 2 power over the right prefontal indicating high level of anxiety. Both groups showed predominance distribution of theta and alpha at the frontal, highest at parietal and temporal area among the $\mathrm{MCl}$. Increasing theta and reduction of delta might be associated with early signs of $\mathrm{MCl}$.

\section{5}

\section{Evaluation of implementation of a psychoaffective Education program to schooled children}

Alfredo Rojas otálora*, Ana Rita Russo de Sánchez

"Universidad del Norte Barranquilla, Colombia

Problem Statement: What effects are achieved in the emotional adjustment of children through d ela implementation of a program of psychoaffective education Research Questions: What is the change in emotional indicators as a result of the application of a psychoaffective education program for children? Purpose of the Study: Assess the effects of the implementation of psycho-affective development program in schooled children on average age of 8 to 10 years. Research Methods: Quasi-experimental method is used to measure before and after with experimental group and control group. Findings: Significant difference in the overall evaluation of emotional factors when comparing the experimental group with the control after program implementation issues found. In the "aggressiveness" significant differences were found in the experimental group, showing a downward trend in the rating. There are also significant changes in the variables "Aggression" and "Anxiety" between experimental and control groups in the post-test Conclusions: The influence of the program was tested in facilitating psycho-affective development in Experimental Group Improved emotional adjustment as a result of the program. The level of psychological well being and decreased emotional difficulties are increased, while it markedly reduced levels of aggression and anxiety. Likely improvement in interpersonal relationships and the expression and management of emotion.

$1^{\text {st }}-4^{\text {th }}$ December, Limak Lara Hotel, Convention Centre, Antalya/TURKEY 
2680

The Moderating Effect of Gender: Traumatic Experiences and Depression in Adolescence

Sílvia Monteiro, Ana Paula Matos*, Sara Oliveira

"Associate Professor, Faculty of Psychology and Educational Sciences, Research

Centre of the Cognitive and Behavioral Studies and Intervention, University of

Coimbra, Rua Colégio Novo, 3000-115 Coimbra, Portugal

Depression may severely affect adolescents in sundry areas. Research demonstrates that girls have greater prevalence of depression than boys since adolescence and that traumatic experiences are predictors of depression. The present study aims to explore if traumatic experiences are predictors of depressive symptoms in adolescence and if gender moderates that relationship. The participants were 319 adolescents aged between 13 and 15 years old, attending the 8 th and 9 th grade in public schools, who participated in a Portuguese study about prevention of adolescent depression. Self-report questionnaires were used to assess traumatic experiences, measured by the Childhood Trauma Questionnaire (CTQ), and depressive symptoms, measured by The Childhood Depression Inventory (CDI). Results showed that the female gender had higher levels of depressive symptoms and also demonstrated a significant correlation between depressive symptoms, emotional abuse and emotional neglect for both genders. Furthermore, these traumatic experiences were predictors of depressive symptoms and a moderating effect of gender on the relationship between emotional neglect and depressive symptoms was found. This moderating effect suggests that for the same levels of emotional neglect girls showed higher levels of depressive symptoms. These findings emphasize the contribution of the emotional component of traumatic experiences on depression.

\section{1}

\section{Confirmatory Factor Analysis of the Resilience Scale (RS13-A) in Portuguese Adolescents}

Anaísa Oliveira, Ana Paula Matos, Maria do Rosário Pinheiro* \& Sara Oliveira *Assistant Professor, Faculty of Psychology and Educational Sciences, Research Centre of the Cognitive and Behavioural Studies and Intervention, University of Coimbra, Rua Colégio Novo, 3000-115 Coimbra, Portugal

The Resilience Scale (Wagnild \& Young, 1993) was developed to assess one's resilience levels. The purpose of the present study is to corroborate the 
unifactorial structure of the Resilience Scale short version for adolescents (Pinheiro \& Matos, 2013) proposed by Wagnild (2009), to explore its reliability and to analyze the association between resilience and depressive symptoms in a Portuguese sample. A Confirmatory Factor Analysis (CFA) was performed in a sample of 308 adolescents, female $(n=167)$ and male $(n=141)$ with ages ranged between 12 and 17 years $(M=13.77 ; S D=1.142)$. The CFA that was conducted led to the construction of a 12 item scale and replicated the one factor solution. The Cronbach's alpha that was obtained revealed to be good (.87). Results showed that resilience was negatively related with depression and is predictive of depressive symptomatology. However, the percentage of explained variance was low. The original one-dimensional structure of the RS short form was confirmed. The results also support that resilience seems to be a protective factor concerning depressive symptoms. Adolescents who obtained higher resilience scores showed lower degrees of depressive symptomatology. These findings can be important for the development of interventions that aim to prevent and treat depression and other psychopathological problems in the adolescent population.

\section{2}

\section{Confirmatory Factor Analysis of the QRI Father's Version in a Portuguese Sample}

Daniela Marques, Maria Rosário Pinheiro, Ana Paula Matos*, Cristiana Marques *Associate Professor, Faculty of Psychology and Educational Sciences, Research Centre of the Cognitive and Behavioural Studies and Intervention, University of Coimbra, Rua Colégio Novo, 3000-115 Coimbra, Portugal

Studies about the specific relationships' quality with the father are scarce. The quality of Relationships Inventory - QRI proposed by Pierce, Sarason and Sarason (1991), evaluates three important dimensions of relationships perceived by the adolescent: Support, Depth and Conflict. The present research aimed to test the structure of QRI father's version (Neves \& Pinheiro, 2006; Matos, Pinheiro \& Marques, 2013 - Portuguese version), with a Confirmatory Factor Analysis and to study the relations between the QRI dimensions. Sample comprised 312 adolescents, 171 females and 141 males, aged between 12 and $17(M=13.77, D P=$ 1.16). The three-factor solution proposed by Pierce et al. (1991) was confirmed in this Portuguese adolescent sample. High positive associations between Support and Depth subscales, $(r=.76)$ and low negative associations between these subscales and the conflict subscale $(r=-.13$ and $r=-.09)$ were found in the father's version of QRI. Support and Depth, in the relationship with the father, seem to be especially related to each other, presenting negative associations with conflict. The results suggest that this instrument, with a three factor structure, can be used in future researches namely to study preventive interventions with adolescents and their families designed to diminish vulnerability to psychopathology, namely depression.

$1^{\text {st }}-4^{\text {th }}$ December, Limak Lara Hotel, Convention Centre, Antalya/TURKEY 


\section{3}

\section{Cognitive Emotional Regulation Strategies and Depressive Symptoms: Gender's Moderating Effect}

Ana Catarina Duarte, Ana Paula Matos*, Cristiana Marques

*Associate Professor, Faculty of Psychology and Educational Sciences, Research

Centre of the Cognitive and Behavioural Studies and Intervention, University of

Coimbra, Rua Colégio Novo, 3000-115 Coimbra, Portugal

Depression is one of the most prevalent psychological conditions among adolescents. The first major depressive episode tends to occur around 15 years old. Between 13 and 15 years old gender differences begin to emerge with girls presenting higher prevalence of depressive symptoms than boys. Problems on emotion regulation and constantly relying on maladaptive cognitive emotion regulation strategies have been pointed as a risk factor for depression and also as a factor that explains gender differences in depressive symptoms, as girls tend to use more maladaptive strategies than boys, such as rumination, selfblaming and catastrophizing. This study aimed to test the moderating effect of gender in the relationship between cognitive emotion regulation strategies and depressive symptoms. 319 adolescents, 13 to 15 years old, participated. Selfreported measures were used to access depressive symptoms (CDI) and cognitive emotion regulation strategies (CERQ). The moderating effect of gender was found in the relationship between positive reappraisal and depressive symptoms, suggesting the importance of enhancing positive reappraisal when facing negative life events, especially for girls. 


\section{CPSYC 2015}

International Congress on Clinical \& Counselling Psychology 13th - 17th October 2015 Istanbul / TURKEY 
The British

Psychological Society

Approved $2^{\text {nd }}$ International Congress on Clinical \& Counselling

Psychology (CPSYC 2014$)$

Abstract Book 